\title{
Reflection on Doing Qualitative Research: Interviewing Silent Women
}

\author{
Najwa Abd Ghafar
}

Faculty of Management, University of Technology, Malaysia

\section{Doi:10.5901/jesr.2014.v4n2p234}

\begin{abstract}
Work-family balance has become one of the most researched topics in the work and family literature. Deemed as an emotionladen topic, investigation of the issue poses challenges and obstacles. This paper describes the challenges the researcher experienced in collecting data for her doctoral dissertation on work-family balance experience of professional Omani women, in the Sultanate of Oman. Situated in a culture where women were historically described as 'the silent one', getting them to open up about their experience poses an additional challenge. Ethnographic open-ended interview had been used as primary data collection tool.
\end{abstract}

Keywords: Work-family Balance; Interview; Women

\section{Introduction}

It has been well-argued that work-family balance is an emotion-laden issue. It is potentially sensitive and not easily spoken about (Shaffer et al., 2011). It is also dynamic and complex thus cannot be gauged by quantitative instrument

(Carlson et al., 2009). Qualitative approach therefore begins to take dominant place due to its strength in soliciting women's perspective and understanding experience in context (Chang et al., 2010; Gilgun, 2012). The approach however does not promise a painless research process.

\section{Ethnographic Interview}

Ethnographic interview is one of the prominent data collection tools in the qualitative study of work-family interface. It was chosen to be the data collection tool in the study of work-family interface experience of professional Omani women. The choice was due to the objective to understand the experience as situated in Omani culture. Culture provides system of meaning that constructs social arrangement (Bradley and Kor, 1993).

There are some features that distinguish ethnographic interview from the non-ethnographic ones. First, it is often conducted as a product of established rapport (O'Reilly, 2009). This rapport allows interviews to be informal and openended, which happen rather naturally than being imposed on them. Second, the informality also implies that there is substantial investment of time, since the researcher cannot always delve straight into the topic and leave, like formal, pre-arranged interviews (ibid, p.127). Duration of an ethnographic interview therefore may vary which can be as short as few minutes or as long as hours. Time is invested not only to build rapport, but also to maintain the relationship. This is important especially when there is always need to return to the interviewees as for in-depth investigation. Third, the informal nature of the interview easily turns it into conversation where exchange of views is enabled (ibid, p.126). This encourages reflexivity on both the researcher and the researched where both have time to delve more deeply, to express their feelings, to reflect, and even to expose their ambivalences. In the light of constructive interpretive ethnographic interview, the interview tends to elicit strong emotions. Fourth, it is normally in-depth and minimally structured so much so that the interviewees are empowered to shape the interview's direction and content (Fielding, 2006). This creates space for the interviewee to focus and elaborate intimate details, recall events, and discuss things that would not be discussed in other circumstances. This feature is distinct as in this type of interview both questions and answers are indeed 'discovered' by the interviewees (Westby, 1990).

\section{Work-family Balance and the Spousal Support}

Strain in work-family interface has been identified as due to several factors. Increasing material aspiration for higher quality goods and service have either forced or aspired women to work (Blair-Loy, 2010; Clarkberg, 2010). The new 
global economy that leads to fierce competition in various industries also has resulted increase of long work-hours (Bailyn et al., 2001) and permeability of boundary between work and family domains (Wajcman et al., 2008; Beninger, 2010). Although both men and women suffer from the strain, substantial number of studies suggests that women bear heavier brunt than men (Fuwa, 2004; Tan, 2008; Blair-Loy, 2010).

Women are known with their strategies to achieve balance. Many choose to limit the number of children in order to return to work when the last child gets to school age (Hakim, 2000). Some continue working while having children, but limit their commitment to work. Women also tend to, - or socialized to choose motherhood-friendly professions in order to integrate work and mother roles (Hakim, 2006). However, albeit the trade-off, balance cannot be achieved singlehandedly. Support and cooperation, be it at work or at home are very much needed to alleviate the work-family stress, as well as to enhance work-family balance.

Studies on support at home name spouse/husband, parents, friends, domestic helpers, and neighbours as sources. However, substantial number of literature focuses on spousal or husband's support considering him as what is termed as 'the significant other' (Abendroth and den Dulk, 2011). Several studies show that while women may have various sources of support, spousal support frequently emerged as the critical support in reducing family to work conflict (Aycan and Eskin, 2005).

Literature on work and family conceptualized two types of support: emotional and instrumental. Emotional support refers to caring behaviour towards the wife's experience in her work-family interface (Nasurdin and Hsia, 2008). This kind of support is expressed by showing concern, by listening to grudges and complaints, and by giving advice, thoughts and guidance. A woman who feels emotionally supported perceives the presence of care and concern from her husband as she shares her experiences and feelings (Burke, 2006). Instrumental support refers to the actual doing that eases the work-family tension. It is the tangible support that a woman receives from her husband like help in household chores and childcare, financial assistance, and when the husband takes leave to attend to their sick child or when she herself falls ill. Instrumental support eases the burden of family demands and enables people to focus at work, whereas emotional support enhances feelings of self-efficacy both at home and at work (Parasuraman et al., 1996). Women who receive spousal support have been found having low family to work negative spill-over, thus lower work-family conflict than those who do not (Nasurdin and Hsia, 2008). Those who have spousal support also have better psychological well-being and higher marital satisfaction (Parasuraman et al., 1992).

\section{Omani Women and Spousal Support}

Studies revealed that culture shapes the way people manifest their support, or support is actually manifested differently according to societies. In individualist societies like Sweden (Forsberg, 2009) and UK (Lu et al., 2010; Sümer et al., 2008), where gender egalitarianism is high, it appears that spousal support is manifested through sharing domestic chores. Both husband and wife run the household together where each of them can and do prepare meals, attend to their children, prepare them and take them to school. Childcare task and statutory leave are shared between husband and wife.

In collective society like Omani, gender-based identity is well-defined where husbands are the bread-winners while women are the homemakers (Al-Barwani and Albeely, 2007). This division is partly traditional as women always have other female relatives living in the same household. To date it is not uncommon to find a household with three generations living under the same roof. To women this is an advantage as they can help each other in domestic chores like cleaning, cooking, and childcare. Although men do take part in childcare and household tasks, it is done more in their past time thus their share is relatively minimal. Many fathers for example do not feel the need to take to take paternity leave as there are other family members attending to the wife and the new born. However as more and more women work away from their family, husbands' support becomes vital. While there are men adjusting to the situation, some are reluctant to review the boundary of gender role division. A columnist in a local newspaper (Oman Daily Observer, $7^{\text {th }}$ May, 2013) warned:

If you have allowed the women to have the wings and go to where they have never been, then the men will have to do the house works and should not care if they are called lesser men or 'inferior'. ( $p .31$ )

Husband doing house works therefore implies various interpretations. While it is definitely a cherished instrumental support to working women, to others, it is a threat to male supremacy. 


\section{Interviewing the Silent Women}

In general, Oman offers a conducive atmosphere for women to success in many aspects. It has always been liberal in its attitude towards women. It is one of the early Gulf States which encourage women to participate in politics when in 1991, the Sultan nominated the first two women as members of the newly reformed council called Oman Consultative Council (OCC). Then, although Kuwait and Bahrain had already had such council, formed in 1963 and 1973 respectively, neither of them had women member. Oman was also the first Gulf state granting its women the right to vote and stand for public office (Al-Haj, 1996). Omani women enjoy more freedom than other Arab sisters in the region. Women behind wheels are typical. They can have license and drive cars. There are women taxi drivers and heavy vehicle instructors. 'Abaya - the black dress is the customary dress, but women can wear other outfits as long as they are socially appropriate.

In spite of these, the country is conservative at heart. J.E.Peterson, Arabian Peninsula and Gulf expert wrote in 2011, that 'Omani society is perhaps the least changed of all the GCC states' (p.105). Tribalism governs local lifestyles where men have the upper hand than women and no major decisions are taken unless after consulting others. Men are considered guardians of women thus many decisions concerning women's lives should be upon the consent of their husbands, or fathers or male relatives (Al-Talei, 2010). In many occasions, there are still many women who seldom leave their houses unescorted by male kin.

In Arab culture, especially in the Gulf region, social visits are heavy (Al-Lamki, 2010). Weekends are especially dedicated to visit parents, relatives and friends. Visits can be of different reasons and occasions; wedding, birth, funeral, people who are coming from or going for long journey, and people who are ill. Looking at this social practice, it appears that there is high level of social transparency where people share their feelings and thoughts. However in reality, unless they know each other well conversations are kept plain and superficial.

Omani women have been described as 'the silent one' by travellers in Oman in the past. Wendell Phillips (1971) who made several trips into the Oman Peninsula and South Arabia between 1953 and 1963 noted that the women always outnumbered the men in terms of population but their existence was mainly domestic. Eickelman (1993), who visited Oman several times between 1979 and 1988, observed that postpartum period (murabbiya) was the heaviest time where women would gather and meet. They however, would neither speak of the birth experience nor the child. In fact, the conversations would casually be on something else like 'a new machine embroidery stitch for pantaloons, a visit to the recently opened Qaboos university in the capital area, even some mild joking or teasing about who is pregnant' (ibid, p.662).

One may criticise that this is peculiar only to foreign eyes, and that these accounts are outdated. However current literature indicates that this silence culture prevails and it has become subject of criticism even by the locals especially the young and educated ones. One of them, Zainab Mohamed Jabur (2008) in her doctorate thesis on Omani women's experience writing in English articulated:

In the Middle East, women, relative to men, have few avenues to express their ideas, and their voices are typically not heard. When Arab women generally, and Omani women specifically, start writing, they have to consider the power of control in its different forms as they choose each idea they cover and each expression they use. (p.1)

Selecting what and what not to say is typical behaviour in collective society. People in collectivist cultures in general are expected to exercise self-discipline, control their emotions, and remain calm and collected even at distress (Hofstede, 1997). Citing from another example, women in collective societies are expected to refrain themselves from expressing grievances even if the disfavoured situations occur frequently (Haj-Yahia and Sadan, 2008). Complaints are considered emotional thus ungrounded, challenging the authority and defying stability. The ultimate objective of the silence is to preserve the stability and the cohesiveness of the society.

\section{Challenges}

This cultural trait has posed challenges in the research process, particularly in the data collection process. In the study of work-family interface among professional Omani women specifically, the researcher found that the silence are attributed by four main factors.

a) First, safeguarding family's dignity or good name is an obligation. Although it is expected of from every social member, the expectation is heavily imposed on women (Al-Talei, 2010). Because of this it is particularly challenging to record their issues of support from family members and spouse. It is a virtue to acknowledge family's support, and even to exaggerate it, but only those with strong personality have the courage to talk about it openly. Women who discuss issues which involve family members can easily be perceived as 
gossiping or back-biting - or worst of all, disclosing 'family secret' (Haj-Yahia and Sadan, 2008).

b) Second, which is related to the first, many of them are married to their cousins. Consanguineous marriages, especially amongst the first cousins are typical in this society even among the educated and professionals (Peterson, 2011; Islam, 2012). It is preferred and respected due to its social and economic advantages. Socially, the marriage simplifies pre-marital negotiations, strengthens family ties, promotes family stability, and offers greater compatibility. Economically, the marriage reduces dowry and preserves property within families (Islam, 2012). In the researcher's study, majority (8 out of 10) of the interviewees are married to their cousins through family arrangements. They did have choice whether or not to agree to the arrangement but many chose to accept it for variety of reasons. Some felt it was better to marry people they knew or people they grew up with than to marry people they did not know at all, or have little knowledge about, even though the cousins are less educated, and earn less than them. Some accepted the arrangement as the cousins are compatible with them - professional and high educated. Being married to cousins or close relatives lead to either two scenarios. First, when they were inquired about their spousal support, they felt hesitant to talk about it as they would actually be talking about their kin who they grew up with. It would be the same case if they were inquired about their parent in-laws, who are actually their uncles and aunts. Talking about them especially if they were perceived as unsupportive would certainly make them ill at ease. Second, it could be that due to the close relationship the participants knew that their spouses were raised in household where boys are not allowed to do women's work. As such, although they reported feeling stressed, they neither showed any wish nor expectation for spousal contribution in domestic chores. They knew from the beginning that they would have to arrange for other sources of support when they need one.

c) Third, in collective societies especially, women are naturally raised to tribute success to others, but blame their own selves for failure (Haj-Yahia and Sadan, 2008). From interviews, the researcher found that women who perceived having difficulties managing work-family interface tend to take it as their personal failures their inability to manage, their lack of parenting skill, and their fatigue; while those who are satisfied attribute their work-family facilitation to support from others - young healthy parents, and/or supportive husbands (who prepare breakfast, help children in studies, put children to sleep etc.). Women readily acknowledged support from their spouses but hesitant to admit experiencing issues due to lack of support from spouses. Instead they tended to blame themselves and express it as their 'incapability to manage'. Some professional women in the study perceived that expectations of domestic duties from their spouses as unacceptable and none of them ever blame the spouses for not taking part in domestic chores. Women also do not expect spouses to help them in domestic chores as they are perceived as women's and not men's jobs.

d) The fourth challenge was the issue of consent and gatekeeper. There were potential participants who initially eager to take part in the study and agreed to be interviewed but later had second thought and eventually withdrew from the study. None of them explained the reason of the withdrawal and the researcher did not persist out of respect to their decision. Later the researcher learnt that actually they had been 'advised' not to participate in the study either by their colleagues or spouses.

There were two cases where women were approached through their spouses who were acquaintances to the researcher's spouse. This happened when the researcher tried to enrich data by gathering them from those of different professional backgrounds. Perhaps, due to the unestablished rapport both attempts failed. One insisted that her participation should not be more than ticking answers in questionnaire sheet while the other put condition for the interview not to be tape-recorded as to 'avoid potential repercussions'.

\section{Recommendations}

Based on the notes gathered throughout the data collection process, few rules of thumb can be used for future guidelines especially to women researchers who plan to embark in the same research topic applying qualitative interview.

a) Build rapport. Rapport is extremely important, and this must be established by the researcher personally. The researcher found that those who have known the researcher for some time were the most open participants. Work-family interface issues can be very personal that realities cannot be uncovered if the researcher was a stranger.

b) Also, in attempt to gain participants from different professional backgrounds the researcher had asked her husband to introduce her to his acquaintances' wives. This did not turn out well. It was found that those who were recommended by him hesitated and refused to be interviewed lest what was shared would leak to the 
males.

c) Take time and give time. First of all, time is very important as rapport takes time to establish (O'Reilly, 2009). Due to this, rapport with potential participants is best established long before the data collection endeavour, and the task becomes much easier with those who have known the researcher for some time. Second, while Omanis are friendly and approachable, being working and having heavy social obligations may limit their time for long interviews. It is important for researchers not to hustle the participants to fit into their frame.

d) Informed consent is important. It is crucial for researchers to be transparent about their research objectives and technique, as well as policy on confidentiality. In this silent culture people rather withdraw from the collaboration than asking for clarification or express their suspicion. It is important for researchers therefore to thoroughly explain their research motives. Westby (1990) advised those who use ethnographic interview to remind the interviewee of the intention and objective of an interview from time to time. This would assure the interviewees that their participation is valuable and their information is confidential.

e) Explain the motive of questions. Compared to paper-and-pencil questionnaire, in-depth open-ended interview is a less popular research activity, as it can be intimidating. However, the researcher found that the participants felt more involved and grew more understanding when the researcher informed the motive of a question. For example, 'Does your husband mind changing your baby's diaper? I am asking this because if he does not, I suppose you can focus on your work at home, or at least you can relax when you are tired'. Without the explanation, the participants may easily feel the interview as interrogation session. Not every question needs to be explained, though. However, after knowing some of them, the participants would understand that every question was genuinely academic.

\section{Conclusion}

Interviewing is a culture-embedded process. To ensure the success of a research endeavour, a researcher must be sensitive to the cultural background of the interviewees and the cultural aspects of the study especially when the researcher is a foreigner. Researching an issue in foreign context demands a researcher to equip herself not only with the literature on the study but the culture per se as well. As daunting as it might be, it is the only means for rewarding journey.

\section{References}

Abendroth, A. and den Dulk, L. (2011). Support for the Work-life Balance in Europe: the Impact of State, Workplace and Family Support on Work-life Balance Satisfaction. Work, Employment \& Society. 25(2), 234-256.

Al-'Omairi, T. and Amzat, I.H. (2012). Women in Omani Society: Education and Participation. International Journal of Sustainable Development. 3(5), 63-80.

Al-Barwani, T. A., and Albeely, T.S. (2007). The Omani Family: Strengths and Challenges. Marriage and Family Review. 41(1-2), 119142.

Al-Haj, A. J. (1996). The Politics in the Gulf Cooperation Council States: The Omani Consultative Council. Middle East Journal. 50(4), 559-571.

Al-Lamki, L. (2010). Stress in The Medical Profession and Its Root in Medical School. SQU Medical Journal. 10(1), 156-159.

Al-Musalmany, N. (7th May, 2013). The Househusband. Oman Daily Observer, p.27.

Al-Talei, R. (2010). Women's Rights in the Middle East and North Africa 2010 - Oman. Retrieved 24 http://www.unhcr.org/refworld/docid/4b99011f86.html

At-Twaijiri, M.I. and Al-Muhaiza, I.A. (1996). Hofstede's Cultural Dimensions in the GCC Countries: An Empirical Investigation. International Journal of Value-based Management. 9, 121-131.

Aycan, Z. and Eskin, M. (2005). Relative Contributions of Childcare, Spousal Support, and Organizational Support in Reducing Workfamily Conflict for Men and Women: The Case of Turkey. Sex Roles. 53 (7/8), 453-471.

Bailyn, L., Drago, R. and Kochan, T.A. (2001). Integrating Work and Family Life: A Holistic Approach. US: MIT Sloan School of Management. Retrieved 22 $2^{\text {nd }}$ January, 2011 from http://web.mit.edu/workplacecenter/docs/WorkFamily.pdf

Beninger, A. (2010). Women in Academia: A Cross-cultural Perspective on Work/Life Balance. Retrieved 22 ${ }^{\text {nd }}$ January, 2011 from http://www.claremonmckenna.edu/berger/pdf/BeningerDissertationWomeninAcademia.pdf

Blair-Loy, M. (2010). Moral Dimensions of the Work-Family Nexus in S. Haitlin, S. Vaisey (eds). Handbook of the Sociology of Morality. Pp.439-453.

Bradley, K. and Khor, D. (1993). Toward an Integration of Theory and Research on the Status of Women. Gender and Society. 7(3), 347-378.

Burke, R.J. (2006). Organizational Culture: A Key to the Success of Work-life Integration in J. Fiona, J.B. Ronald and W. Mina (eds). 
Work-life Balance: A Psychological Perspective. Pp. 235-260.

Carlson, D.S., Grzywacz, J.G., and Zivnuska, S. (2009). Is Work-family Balance More than Conflict and Enrichment? Human Relations. 62(10), 1459-1486.

Chang, A., McDonald, P. and Burton, P. (2010). Methodological Choices in Work-life Balance Research 1987 to 2006: A Critical Review. The International Journal of Human Resource Management. 21(13), 2381-2413.

Clarkberg, M. (2010). More Dual-Earner Couples, Working Harder Than Ever. Retrieved 1 st April, 2012 from http://www.dol.gov/oasam/programs/history/herman/reports/futurework/conference/families/couples.htm

Eickelman, C. (1993). Fertility and Social Change in Oman: Women's Perspectives. Middle East Journal. 47(4), 652-666.

Fielding, N.G. (2006). Ethnographic Interviewing in Victor Jupp (ed). The SAGE Dictionary of Social Research Methods. UK: The SAGE Publications Ltd. (pp.100-102).

Forsberg, L. Managing Time and Childcare in Dual-Earner Families: Unforeseen Consequences of Household Strategies. Acta Sociologica. 52(2), 162-175.

Fuwa, M. (2004). Macro-level Gender Inequality and the Division of Household Labor in 22 Countries. American Sociological Review. 69(6), 751-767.

Gilgun, J.F. (2012). Enduring Themes of Qualitative Family Research. Journal of Family Theory and \& Review. 4(2), 80-95.

Haj-Yahia, M.M. and Sadan, E. (2008). Issues in Intervention with Battered Women in Collectivist Societies. Journal of Marital and Family Therapy. 34(1), 1-13.

Hakim, C. (2000). Work-life Choices in the 21st Century: Preference Theory. Oxford: Oxford University Press.

Hakim, C. (2006). Women, Careers and Work-life Preferences. British Journal of Guidance and Counselling. 34(3), 279-294.

Hofstede, G. (1997). Cultures and Organizations: Software of the Mind. New York: McGraw-Hill.

Islam, M.M. (2012). The Practice of Consanguineous Marriage in Oman: Prevalence, Trends and Determinants. Journal of Biosocial Science. 44, 571-594.

Lu, L., Cooper, C.L., Kao, S., Chang, T., Allen, T.D., Lapierre, L.M., O'Driscoll, M.P., Poelmans, S.A.Y., Sanchez, J.I., and Spector, P.E. (2010). Cross-cultural Differences on Work-to-family Conflict and Role Satisfaction, a Taiwanese-British Comparison. Human Resource Management. 49(1), 67-85.

Mohamed Jabur, Z. (2008). A Qualitative Study of Omani Muslim Women's Perceived Experiences as Writers in English as Second Language. Doctor Philosophy. Indiana University of Pennsylvania.

Nasurdin, A.M. and Hsia, K.L. (2008). The Influence of Support at Work and Home on Work-family Conflict: Does Gender Make a Difference? Research and Practice in Human Resource Management. 16(1), 18-38.

O'Reilly, K. (2009). Key Concepts in Ethnography. UK: SAGE Publications Ltd.

Parasuraman, S., Greenhaus, J.H. and Granrose, C.S. (1992). Role Stressors, Social Support and Well-being Among Two-career Couples. Journal of Organization Behavior. 13(4), 339-356.

Parasuraman, S., Purohit, Y.S., and Godshalk, V.M. (1996). Work and Family Variables, Entrepreneurial Career Success and Psychological Well-being. Journal of Vocational Behavior. 48, 275-300.

Peterson, J.E. (2011). Oman Faces the Twenty-first Century in Tétreault, M. Okruhlik, G., and Kapiszewski, A. (eds) Political Change in the Arab Gulf States. London: Lynne Rienner Publishers. Retrieved 18 ${ }^{\text {th }}$ December, 2011 from www.jepeterson.net/sitebuildercontent/sitebuilderfiles/Peterson_Oman_Faces_21st_Century.pdf.

Phillips, W. (1971). Unknown Oman. Beirut: Librairie Du Liban.

Shaffer, M.A., Joplin, J.R.W. and Hsu, Y. (2011). Expanding the Boundaries of Work-family Research: A Review and Agenda for Future Research. 11(2), 221-268.

Sümer, S., Smithson, J., Guerreiro, M., and Granlund, M. (2008). Becoming Working Mothers: Reconciling Work and Family at Three Particular Workplaces in Norway, the UK., and Portugal. Community, Work \& Family. 11(4), 365-384.

Tan, S.J. (2008). The Myth and Realities of Maternal Employment. in Marcus-Newhall, A., Halpern, D.F. and Tan, S.J. (Eds.), The Changing Realities of Work and Family. US: Wiley-Blackwell Publishing.

Wajcman, J., Bittman, M. and Brown, J.E. (2008). Families without Borders: Mobile Phones, Connectedness and Work-home Divisions. Sociology. 42(4), 635-652.

Westby, C.E. (1990). Ethnographic Interviewing: Asking the Right Questions to the Right People in the Right Ways. Journal of Childhood Communication Disorders. 13(1), 101-111. 